\title{
JOEY E SUA MECÂNICA DO “CORPO": UM OLHAR SOBRE A ESCOLHA DO SUJEITO AUTISTA DE SE ALIENAR PARCIALMENTE À LINGUAGEM
}

Elisangela Maria da SILVA ${ }^{1}$

\section{DOI: http://dx.doi.org/10.21165/gel.v18i3.3151}

Resumo: O objetivo do presente estudo é discutir a escolha do sujeito autista: a de se alienar parcialmente ao Outro, partindo das contribuições teóricas de Maleval no tocante ao autista não deixar de manter um domínio sobre o objeto $a$, seja por retenção ou pela construção de borda. Metodologicamente, realizamos uma discussão teórica sobre as defesas autísticas como proteção da angústia. Numa tentativa de abordar empiricamente o objetivo proposto, recorremos, a título de exemplificação, a recortes do caso Joey de Bruno Bettelheim.

Palavras-chave: Escolha. Constituição subjetiva. Autismo.

1 Centro Universitário Maurício de Nassau, Olinda, Pernambuco, Brasil; elisangelasilva1718@gmail.com; https://orcid.org/0000-0001-8404-5190 
- | Joey e sua mecânica do "corpo": um olhar sobre a escolha do sujeito autista de se alienar parcialmente à linguagem

\title{
JOEY AND HIS "BODY" MECHANICS: A LOOK AT THE AUTISTIC SUBJECT'S CHOICE TO PARTLY ALIENATE HIMSELF TO THE LANGUAGE
}

\begin{abstract}
This study aims to discuss the autistic subject's choice to partially alienate himself/herself from the Other, based on Maleval's theoretical contributions regarding the autistic subject's ability to maintain domination over object $a$, either by retention or by the construction of an edge. Methodologically, we've carried out a theoretical discussion about autistic defenses as protection against distress. In an attempt to empirically approach the proposed objective, we've resorted, as an example, to clippings from Bruno Bettelheim's Joey.
\end{abstract}

Keywords: Choice. Subjective constitution. Autism.

\section{Introdução}

[...] creio que, ao devolver a causalidade da loucura $a$ insondável decisão do ser em que ele compreende ou desconhece sua libertação, à armadilha do destino que o engana quanto a uma liberdade que ele não conquistou, não estou formulando outra coisa senão a lei de nosso devir. (LACAN, 1998, p. 178, grifo nosso).

Todos os seres humanos, mesmo antes de nascer, são afetados pela linguagem, o que inclusive concede a possibilidade da alucinação e do autoerotismo. Isso significa que nascemos num mundo onde a linguagem nos precede e nos determina. No sujeito autista, isso não é diferente e ainda que ele se defenda da linguagem, ela ecoará em seu corpo. É nesse sentido que concordamos com Maleval (2015, p. 21) quando diz que o sujeito autista está na alienação em relação ao Outro, mas que essa "[...] alienação significante não é assumida pelo sujeito". Desse modo, o sujeito autista se põe em posição de promover um intenso trabalho de distanciamento desse Outro. Se pondo numa escolha, talvez insondável, do ser em seu posicionamento de não se deixar perder.

É sobre essa aceitação parcial, essa aceitação não assumida da alienação que discutiremos neste estudo. Discutindo também como o sujeito autista não deixa de manter um domínio sobre o objeto $a$, seja retendo-o ou construindo uma borda. Para tanto, utilizamos recortes do caso Joey de Bruno Bettelheim, a título de exemplificação. 


\section{Aspectos gerais do caso Joey de Bettelheim}

O caso Joey é relatado no livro A Fortaleza Vazia (1987), de Bettelheim. Joey era um garoto de 9 anos quando foi atendido na Escola Ortogênica de Chicago (EUA) - uma instituição para o acolhimento de crianças que sofriam de distúrbios afetivos graves, especialmente autistas.

Segundo Bettelheim (1987), Joey não se sentia uma pessoa, mas sim um dispositivo mecânico. Ele criou seu próprio mundo onde não havia sentimentos, só máquinas. $O$ casamento dos pais de Joey foi uma tentativa de solucionar traumas de casos amorosos anteriores, a mãe amou um homem que morreu na Segunda Guerra Mundial e o pai também teve um amor infeliz. Apesar de cada um dos genitores encontrarem-se traumatizados pela perda de um companheiro que, para eles, significava uma profunda relação emocional, ambos decidiram que uma escolha racional iria ajudá-los. Diante disso, o que pretendiam do casamento era esquecer a dor de cada um, essa dor não partilhada.

Para o autor, ambos não estavam preparados psicologicamente para ter um filho. A mãe não permitiu que a maternidade provocasse qualquer emoção: "Nunca me dei conta que estava grávida". Também o nascimento dele "não fez qualquer diferença" (BETTELHEIM, 1997, p. 259). Em partes gostou de ter um filho, pois diminuiria sua solidão, mas sentiu-se apavorada com a responsabilidade da maternidade e com medo de não ser uma boa mãe. Desse modo, não quis cuidar de Joey, não quis vê-lo e nem o amamentar, considerava-o uma coisa.

Para Bettelheim (1987, p. 260), o acolhimento de Joey nem foi amor, nem rejeição, nem ambivalência. Devido à ansiedade absoluta da mãe, Joey foi pura e simplesmente ignorado. Ao ir para casa, Joey "chorava quase o tempo todo", sofria de cólicas, alimentavase a cada quatro horas rigorosamente, era trocado quando necessário. Ninguém brincava com ele e nem o embalava para dormir.

Com o passar do tempo, passou a bater violentamente a cabeça, balançando-a ritmicamente para frente, para trás e para os lados. O pai era militar transferido para outra unidade de trabalho e descarregava frequentemente sua irritabilidade no bebê. Com um ano e meio, Joey e sua mãe mudaram-se para a casa dos avós maternos, que observaram uma mudança estranha e evidente no comportamento do menino. Notaram um envolvimento com máquinas, principalmente, com um ventilador que ganhou dos pais em seu aniversário de um ano. Joey desmontava e remontava o presente repetida e incansavelmente. 
- | Joey e sua mecânica do "corpo": um olhar sobre a escolha do sujeito autista de se alienar parcialmente à linguagem

Consoante Bettelheim (1987), o interesse pelo ventilador é justificado pelo fato de Joey ser levado desde muito cedo para o aeroporto quando seu pai embarcava e desembarcava de suas viagens a trabalho. Tais viagens tiveram grande significado para o garoto.

Joey falava, embora não se comunicasse, sua linguagem foi se tornando abstrata e despersonalizada e aos quatro anos de idade foi encaminhado para uma escola maternal para crianças perturbadas. A orientadora infantil reconheceu a necessidade de um tratamento psiquiátrico para o menino, já que vivia isolado e só se interessava por movimentos giratórios.

$\mathrm{Na}$ clínica, Joey foi diagnosticado autista, sendo-lhe proposto um tratamento psicoterápico individual tanto para a criança como para os pais. Os anos de terapia para os pais proporcionaram um progresso e melhora na relação do casal até um nível satisfatório. Eles tiveram mais dois filhos não autistas: uma menina, seis anos mais nova que Joey, e um menino, treze anos mais novo.

Durante a terapia na escola maternal, Joey apresentou alguns progressos, passou a reconhecer a existência de sua terapeuta e até a interagir um pouco com ela e após um ano passou a chamá-la pelo nome. Mas, seis anos era a idade limite permitida para a escola maternal, Joey, então, passou os dois anos seguintes em um internato, perdendo muito do progresso conquistado. O menino voltou a um mundo despersonalizado em que dirigia-se somente à mãe, manifestando-se por murmúrios.

Joey ficou em casa enquanto aguardava ser admitido na Escola Ortogênica. O menino não falava mais nem "mamãe" e sua relação com ela só piorou, porque toda a atenção era direcionada à filha mais nova. O garoto foi mergulhado em uma raiva, tornando sua própria vida insuportável, levando-o a cometer uma tentativa de suicídio.

Ao chegar à escola de Bettelheim (1987, p. 254), Joey apresentava estatura menor que o esperado, estava magro, parecia frágil, "um homem mecânico". O autor defende que Joey encontrou um mundo em que sentimento era sinônimo de sofrimento, então criou um mundo próprio, sem lugar para sentimentos. Interessava-se pelas máquinas, por serem mecânicas e isentas de emoções.

Para se alimentar, Joey ligava a si mesmo com um fio imaginário a uma tomada imaginária antes de comer, porque só a corrente fazia funcionar seu aparelho digestivo. Com o passar do tempo, Joey se aproxima de duas orientadoras e de um professor, a saber, Fae, Bárbara e Lou. Foi apenas por volta dos doze anos que Joey deixou de agir como um aparelho mecânico para ser uma criança humana, tornando-se um recém- 
nascido. Após nove anos na escola, ele já era capaz de sentir emoções e desejava ser amado, demonstrava vontade de dirigir sua própria vida e comunicou que queria voltar a morar com seus pais para recomeçar sua vida em família.

Joey completou sua educação em uma escola técnica e após o término de seus estudos, pediu aos pais para visitar a escola de Bettelheim indo sozinho até Chicago. Nessa visita, Bettelheim pediu a Joey o consentimento de publicar sua história.

Agora que conhecemos alguns aspectos do caso Joey, passaremos à discussão da constituição do sujeito e de sua relação com a linguagem. Tomamos para ilustração fragmentos do caso Joey, tecendo reflexões sobre como a criança autista parece optar por não seguir as regras de partida da linguagem tal como era esperado.

\section{A encarnação da linguagem ou posição diante do Outro}

Ao falarmos da encarnação da linguagem, referimo-nos à constituição do sujeito, na qual, conforme Leite e Souza Jr. (2021), pressupõe-se um sujeito de linguagem, um sujeito no qual o tesouro da língua irá se depositar a conta-gotas, letra a letra, no decorrer desse misterioso processo de transmissão denominado aquisição de linguagem.

Quanto a esse último ponto, os trabalhos sobre aquisição de linguagem desenvolvidos por Lemos (1998, 2001 e 2002) e colaboradores, que tratam da trajetória da criança de infans a falante através do encontro com o campo de saber da Linguística Estrutural europeia e com a Psicanálise Freud lacaniana, passam a contemplar a emergência do sujeito na língua ao levar em consideração um sujeito do inconsciente que emerge na cadeia significante.

É a linguagem, ou melhor, le langage - e nela está incluído o outro enquanto semelhante e, na sua diferença, enquanto "outro" - que precede e determina a transição da criança do estado de infans para o de falante. Em outras palavras, a criança é capturada por le langage, atravessada e significada como é pela parole do outro, matriz de sua identificação como semelhante - e membro da comunidade linguística e cultural - e como dissemelhante, referido a uma subjetividade figurada como individual. (LEMOS, 2001, p. 27).

A partir da releitura de Saussure (2006, p. 31), era possível incluir uma “ordem própria da língua", principalmente no que tange à noção central de funcionamento da língua. Desse modo, foi possível a Lemos (1998) retomar os dois processos trazidos por Jakobson (1971), os processos metafóricos e metonímicos que respondem pelo funcionamento da 
- | Joey e sua mecânica do "corpo": um olhar sobre a escolha do sujeito autista de se alienar parcialmente à linguagem

língua e são entendidos, desde então, como mecanismos descritivos e explicativos das mudanças que operam na fala da criança.

Convém destacar que o Saussure convocado por Lemos (2002, p. 51) é aquele Saussure que sobrevive pela leitura lacaniana, em que "[...] se privilegiou a teoria de valor, o conceito de sistemas como sistema de relações - e não de unidades - regidas pela pura diferença".

Uma palavra pode ser trocada por algo dessemelhante: uma ideia; além disso, pode ser comparada com algo da mesma natureza; uma outra palavra. Seu valor não estará então fixado, enquanto nos limitarmos a comprovar que pode ser trocada por este ou aquele conceito, isto é, que tem esta ou aquela significação; falta ainda compará-la com os valores semelhantes, com as palavras que se the podem opor. Seu conteúdo só é verdadeiramente determinado pelo concurso do que existe fora dela. Fazendo parte de um sistema, está revestida não só de uma significação como também, e sobretudo, de um valor, e isso é coisa muito diferente. (SAUSSURE, 2006, p. 134).

Dessa forma, a autora destaca que a teoria do valor de Saussure, oferece

[...] a possibilidade de ir além da consideração das unidades como primitivos linguísticos, de considerar qualquer classe de unidades linguísticas como derivadas de relação [...]. Tal noção de valor impossibilita o acesso direto às coisas em si mesmas, ou, em outras palavras, a possibilidade de tratá-las como idênticas a si mesmas. (LEMOS, 1998, p. 156).

Nesta direção, o encontro e a releitura de Saussure possibilitaram a Lemos (1998, 2002) abordar a mudança na fala da criança de um ponto de vista estrutural, porque ele oferece uma visão de linguagem compatível tanto com questões epistemológicas quanto com os argumentos empíricos da perspectiva seguida pela pesquisadora, a saber, o Interacionismo. Desse modo, a pesquisadora encontra o linguístico como a teoria linguística que permite ver aquilo que emerge como singular na fala da criança como: as repetições, o erro, as dificuldades e recusas em se deixar transitar por uma língua.

Assim, vemos que os trabalhos sobre aquisição de linguagem, desenvolvidos por Lemos (1998 e 2002) ao longo de vários anos têm demonstrado a íntima dependência da fala da criança em relação à fala do adulto (mãe), indicando processos de especularidade que descrevem o percurso entre a posição da criança alienada à fala do outro até a possibilidade de assumir a função da fala enquanto submetida à língua - separação. 
É importante destacar que esse processo não se dá de modo pacífico. E por mais cuidado que se despenda ou tome, é forçosamente que a língua se instala na criança, isso porque esse processo de engendramento do sujeito acontece não pelo Outro, mas pela falta encontrada nesse Outro, num processo de hiância por dois movimentos distintos denominados por Lacan (2008a) de alienação e separação.

A alienação consiste no tipo de véu que condena o sujeito a uma escolha e qualquer que seja a escolha que se opere, um dos elementos desaparece. Ao exemplificar como se dá essa escolha, Lacan (2008b, p. 207) aponta uma questão em que o sujeito é confrontado: "[...] a bolsa ou a vida! Se escolho a bolsa, perco as duas. Se escolho a vida, tenho a vida sem a bolsa, isto é, uma vida decepada".

Para Leite (2000, p. 46), tal escolha é forçada, considerando que há apenas uma escolha real, a vida, que se escolhida condena o sujeito a uma vida em falta; caso opte pela bolsa perderá tudo. Esse véu, portanto, exclui sempre um só e mesmo termo - a bolsa. "Ao substituirmos os termos dessa escolha por aqueles que nos interessam na constituição do sujeito, temos: Ser (sujeito) e Outro (sentido). Desse modo, a alienação se dá entre sentido e não-sentido".

A separação é introduzida pela via da falta, no intervalo que corta os significantes, nas faltas do discurso do Outro e que chamamos de desejo (LACAN, 2008a). Nesse sentido, o Outro também é faltoso e demonstra isso ao não responder ao ser do sujeito. Desse modo, "[...] o desejo do homem é o desejo do Outro, uma vez que o modo de sua estruturação se faz por enganchamento do desejo do Outro" (LEITE, 2000, p. 46).

Nesta direção, o sujeito da psicanálise, ao mesmo tempo em que se aliena ao outro, dele se separa para que possa comparecer de maneira singular, tratando-se de uma subjetividade sempre em constituição. É um sujeito que não está pronto e ao ser imerso na linguagem segue um movimento contínuo em relação ao Outro. Desse modo, o sujeito da psicanálise é o resultado dos discursos aos quais é submetido.

Portanto, não há como falarmos do sujeito sem falarmos do Outro, visto que o Outro representa, conforme Silva (2015, p. 22), “[...] não somente outro sujeito, mas a língua, a cultura e as relações estabelecidas pela sociedade ao longo da história da humanidade, ou seja, todos os significantes capazes de constituir o sujeito pela linguagem".

Nesse começo da relação mãe bebê, uma mãe faz do seu bebê único objeto do gozo e, nessa identificação com ele, desenvolve um modo particular de comunicação, expressando seu alto grau de sensibilidade, enunciando a criança como causa de seu desejo, antecipando-o enquanto sujeito e nomeando sua demanda. Desse modo, as 
- | Joey e sua mecânica do "corpo": um olhar sobre a escolha do sujeito autista de se alienar parcialmente à linguagem

palavras e os significantes, que são responsáveis por criarem sentido, cingem o corpo da criança e provocam efeitos. Passado esse tempo de alienação, surge o desejo de ir mais além de uma primeira inscrição e, a partir da falta no Outro, a criança se questionará sobre o que o adulto deseja, surgindo, então, um enigma em torno do desejo do Outro. É essa incompletude no Outro, essa hiância que anuncia a existência de um desejo. "É nesse ponto de falta que o sujeito tem que se reconhecer" (LACAN, 2008a, p. 262).

Como se pode observar, o desejo do Outro faz surgir na criança interrogações, enigmas e é nessa falta, nessa hiância que a criança poderá se mover da posição de petrificada, alienada em relação aos significantes do Outro, para a posição de sujeito do desejo. Assim, se o que vem do outro é responsável pelo que, em nós, há de mais fundamental, estruturante e organizador, cumpre notar que não é de uma maneira qualquer que isso nos chegou um dia. É primordial que haja alguém que suponha na criança um falante, que a coloque no lugar de interlocutor, a partir do qual, num segundo momento, ela será capaz de endereçar-se a um outro. Mas cabe ao sujeito a advir conceder, consoante Catão e Vives (2011, p. 85), “[...] seu primeiro sim à operação de alienação, que terá que ser confirmada várias vezes". Esse movimento aponta que cada sujeito tem com o objeto uma relação particular e que, diante do Outro da linguagem, o sujeito possui diferentes possibilidades de respostas que definirão a sua posição no campo simbólico.

O funcionamento psíquico se estrutura em tempos sucessivos de afirmação e de negação. As diferentes modalidades de negação descritas por Freud darão acesso às diferentes estruturas psíquicas: Verdrängung (recalque) a neurose, Verwerfung (forclusão) a psicose e Verleugnung (renegação, recusa da realidade, recusa ou desmentido) a perversão. (CATÃO; VIVES, 2011, p. 85).

Assim, vemos que o aforismo de Lacan sobre o inconsciente ser estruturado como uma linguagem, além de revelar o surgimento da linguagem no ser falante, aponta, estruturalmente, quão traumático pode ter este acesso do ser vivente na linguagem. Mostrando que há aí, nos dois tempos constitutivos da subjetividade, uma escolha a ser feita: a de abrir mão do gozo vocal. E, consoante Maleval (2017, p. 106), é essa "a condição da incorporação da voz do Outro". Partindo disso se operará a incorporação da voz. Mas, a vontade inicial de controle de toda e qualquer perda, realizada pelo autista, barra sua alienação no significante, resultando numa ausência de regulação do gozo do vivo.

Em outras palavras, nessa lógica de perda há um corte que pode ser pensado como possibilidade de aquisição da função de fala, na qual o bebê deverá abandonar o fluxo contínuo das vogais e aceitar a entrada das consoantes que funcionam verdadeiramente como cortes de tal fluxo. Desse modo, a entrada na linguagem e o funcionamento a partir 
de elementos significantes que em sistemas se organizam para produzir significações implicará a perda de certo gozo no corpo (HELLER-ROAZEN apud LEITE; SOUZA JR., 2021). E esse gozo que confronta a criança com uma demasia de excitação pode ser destrutivo, caso não seja limitado.

Vemos, então, que a encarnação da linguagem inicia pela incorporação da voz do Outro, mas isso só pode ocorrer com o consentimento da criança. A criança autista não cede sobre o gozo da voz e, em função disso, sofre de um excesso de voz. Essa recusa não se dá somente com a voz. É comum constatar-se na história dessas crianças uma recusa em trazer os objetos pulsionais (o olhar, a voz, as fezes e o alimento) para a troca, é o que relata Joey, no que concerne à voz e ao olhar:

Primeiro colocamos cera nos ouvidos. Isso nos protege e nos tapa os ouvidos de maneira que não podemos ouvir coisas que não queremos. Colocamos cada vez mais cera para termos a certeza de que não ouvimos; isso nos deixa surdos. A surdez espalha-se tanto que todo mundo fica surdo e ninguém é capaz de ouvir. Leva a cegueira, então as pessoas ficam surdas e cegas. (BETTELHEIM, 1987, p. 345).

A fala de Joey parece confirmar as considerações de Maleval (2018) a respeito da angústia gerada no autista em interagir com os outros, apontando que esta não é da ordem da incompreensão das relações sociais, mas de uma angústia irracional que o sujeito não domina. O que aponta que a escolha do sujeito autista indica uma maneira de lidar com o Outro que é sustentado a duras penas por um sujeito que tenta escapar do destino de ter uma vida fugaz, em intervalos e desaparecer entre dois significantes.

De acordo com o exposto acima, a criança autista não aceita perder o objeto pulsional voz, a qual permanece como objeto $a$ não separado e se manifesta regularmente no grito e na ecolalia, formas mais frequentes de produção verbal da criança autista. E esta última (ecolalia) mostra claramente que a criança autista não é indiferente às palavras do Outro, mas demasiadamente sensível a elas.

Ainda sobre a recusa de trazer os objetos pulsionais para a troca, Maleval (2018) esclarece que pode ser demonstrada no mutismo, quando uma resposta lhe é exigida, e no tapar as orelhas quando lhe falam. Para o autor, esses dois modos diferentes de agir do autista têm em comum evitar o uso da voz e que diante de tais condições a entrada na linguagem, pelo autista, passará por dois canais: balbucios pobres e ecolalias que desconsideram a significação e, principalmente, a escrita que exclui o gozo vocal. Disto resulta uma separação entre emoções e o intelecto. 
- | Joey e sua mecânica do "corpo": um olhar sobre a escolha do sujeito autista de se alienar parcialmente à linguagem

Para o referido autor, nesta primeira defesa do quadro do autismo infantil precoce há uma separação entre o sujeito e sua vida emocional. Algo que parece ser revelado na chegada de Joey à Escola Ortogênica.

Da primeira vez que encontramos o Joey, parecia muito baixo e frágil para seus nove anos e meio. Parecia ser só olhos num corpo dolorosamente magro, olhos escuros e sofredores fitando vagamente o nada. Se por acaso fazia algo, parecia funcionar por controle remoto - um homem mecânico dirigido por máquinas que haviam sido criadas por ele e que lhe escapavam ao controle. (BETTELHEIM, 1987, p. 254).

Notemos o quanto subsiste aí uma sensação de inércia da parte de Joey, uma vez que sua energia parece vir de suas máquinas. Sobre isso, Maleval (2017) vai apontar que como o simbólico não chega a amainar o caos do mundo e das emoções do autista, alguns desenvolvem estratégias notáveis a sua debilidade e procuram, com isso, pelo controle e pelo absoluto.

Prosseguindo nesse caminho de procura pelo controle e pelo absoluto, Maleval (2018) postula que o autista não gosta dos equívocos da língua e para se prevenir, quando procura se comunicar, ele se apega a uma língua factual que gostaria que fosse tão precisa quanto um código e às vezes ele elabora uma língua para o seu próprio uso, supondo que ela seria mais apropriada à expressão de suas emoções. Dessa forma,

[...] a criança autista cria uma linguagem de acordo com a experiência emocional que tem do mundo - o que é uma realização intelectual. Longe de não saber como utilizar corretamente a linguagem, significa uma decisão espontânea de criar uma linguagem que se coadune com a forma como ela experimenta as coisas - e apenas as coisas, não as pessoas. (BETTELHEIM, 1987, p. 262, grifo nosso).

Sobre esta linguagem particular, Maleval (2018) destaca que aparece desde as primeiras vocalizações das crianças autistas e mesmo que seja compreendida por seus próximos, ela não é nem um pouco forjada para servir à comunicação, tratando-se mais de uma busca de satisfações verbais solitárias levemente acompanhadas de uma busca de ordem e clareza. Bettelheim (1987, p. 254-261) nos relata que "Joey era uma criança autista que falava, embora não se comunicasse. [...] A linguagem de Joey se dirigia exclusivamente para ele mesmo". Assim, vemos que Joey forja uma linguagem, mas não para compartilhála. 


\section{O retorno do gozo na borda ou uma mecânica do "corpo"}

Vimos que o autismo se enraíza, muito cedo, em uma angústia em interagir com os outros e que esta não é da ordem da incompreensão das relações sociais, mas de uma escolha mais radical, comandada por um gozo imperioso. Vimos também que a criança autista se recusa a ceder o gozo vocal, resultando uma ausência de regulação do gozo pelo simbólico. Sobre esse aspecto, Maleval (2017, p. 123) explica que, no sujeito autista, "[...] o gozo do vivo não se prende ao significante - de modo que suas sensações e suas imagens carecem de elementos reguladores".

Para o referido autor, como o gozo do sujeito autista não é regulado pelo simbólico, não há, praticamente, investimento dele (autista) na realidade social e é nisso que se encontra empenhado. Aqui, estamos diante da segunda defesa do domínio do quadro autístico infantil precoce: o retorno do gozo na borda que, consoante Maleval (2017), encontra seus desenvolvimentos na síndrome de Asperger, com as estupendas utilizações do duplo e do objeto, ou as notáveis construções do Outro de síntese.

Com efeito, o sujeito autista, por não ter cedido o objeto voz, no lugar da perda por não se tornar falta, se impõe como um lugar real que a criança tentará tapar com objetos autísticos, que permanecem engatados ao corpo. Esses objetos autísticos servem como um rochedo que separa a criança autista do Outro. Desse modo, os objetos autísticos funcionariam como uma prisão de gozo, como um abrigo afastando-o do mundo (ORRADO; VIVES, 2021).

É nesse sentido que Maleval (2017, p. 124), ao postular sobre o nascimento de uma borda, afirma que o autista se esforça para controlar o gozo desvairado, desviando-o do corpo e fazendo-o servir à sua segurança e às suas defesas. Por isso, o sujeito autista "[...] dedica-se à criação de uma borda que separe seu mundo tranquilizante e controlado do mundo caótico e incompreensível". Desse modo, a borda autista é uma formação protetora, uma fronteira entre o mundo pessoal do sujeito autista e o resto do mundo, ela se fundamenta em uma perda dominada, que não fecha um buraco, mas delimita-o, ou seja, circunscreve-o. Mas, para que isso ocorra é preciso que a criança autista esteja em condições que lhe permitam desenvolver as potencialidades da borda.

Neste sentido, a construção de uma borda é uma das respostas possíveis frente à demasia de um gozo em jogo, ela (borda) é uma forma de capturá-lo para evitar que o gozo retorne no corpo. Assim, essa borda é simultaneamente separadora e protetora, já que o sujeito autista é muito sensível à menor modificação e o gesto estereotipado funcionaria como uma forma de apagar toda e qualquer possibilidade de surpresa. 
- | Joey e sua mecânica do "corpo": um olhar sobre a escolha do sujeito autista de se alienar parcialmente à linguagem

Ainda sobre o tratamento do gozo pulsional, Maleval (2017, p. 129) postula as especificidades do duplo, afirmando que este se impõe para o sujeito autista como uma estrutura privilegiada para sair da solidão, uma vez que sua conformidade é tranquilizante e delimitadora do gozo. Desse modo, o duplo se constitui num "[...] objeto familiar, sempre controlado, ou considerado como um 'amigo' inerente ao mundo assegurado, [...] que pode ser utilizado como suporte de uma enunciação artificial". Vejamos o que descreve Bettelheim (1987, p. 284) sobre as prevenções de Joey:

Quando Joey veio viver conosco, ir ao banheiro, assim como qualquer outro ato da sua vida, cercava-se de complicadas prevenções. Tínhamos de ir com ele ao banheiro; tinha de tirar toda a roupa; não podia sentar-se, mas apenas acocorar-se sobre o tampo e tinha de tocar a parede com uma das mãos, à qual prendia as lâmpadas que Ihe forneciam energia para sua eliminação. Com a outra mão tinha de segurar o pênis enquanto defecava, e mantê-la perto do ânus quando urinava. Foi esse o primeiro indício que tivemos do quanto ele receava, que abrindo demasiado o corpo, este perdesse todo o seu conteúdo, que todo o seu 'recheio' se esvaísse. O terror que experimentava quando algo Ihe saía do corpo revelava o quanto receava perder o que quer que fosse.

Para Bettelheim (1987), a atividade manipulatória dos objetos pela criança autista pode revelar muito sobre o que se passa em sua intimidade, por isso, o psicanalista não julga necessário privar o sujeito autista de seus objetos. Assim, vemos, pela descrição, que a defecação de Joey é alimentada pelo seu duplo, as lâmpadas, que fornecem uma dinâmica vital e essencial para a regulação do objeto anal. Desse modo, o fenômeno do corpo é deslocado e dominado pela construção e manipulação desse objeto que é externo.

Ao localizar seu gozo em um objeto externo, o sujeito autista mostra que ele alimenta uma relação desordenada com o gozo de seu próprio corpo. Entretanto, por não dispor da função do significante unário, ele não a codifica em um índice do objeto perdido: ele se separa dela pela produção de um objeto concreto. (MALEVAL, 2018, p. 28).

Como vimos o corpo do sujeito autista é a sede de um gozo invasivo que ele tenta fechar de todas as formas, seja fechando os olhos, tapando os ouvidos ou retendo as fezes. E a borda funciona como um operador de captura e tratamento do gozo, podendo encarnar em um objeto concreto, imagem, pessoa ou um conjunto temático de signos. Desse modo, o sujeito autista conservaria o objeto $a$ não no bolso, mas separado da mão, 
alocado em um "en-forma", como um objeto de gozo que continua presente (MALEVAL, 2018).

Entre a nomeação do objeto e sua negação operada pelo sujeito autista, produz-se uma cutucação do objeto - a qual procura apagá-lo, e não fazê-lo retornar. Todos os clínicos notaram a frequência do recurso a tais condutas de cutucação nas crianças autistas. Essas condutas dão a elas uma sensação de segurança, testemunhando um controle do objeto. Essas condutas parecem aplicar ativamente a lógica do signo, assegurando-se primeiro da presença do objeto, daí afetando-o com certa negatividade - entretanto, sem proceder a uma assunção da sua perda. Elas operam para enquadrá-lo simbolicamente e depois disso ele pode encontrar lugar no mundo protegido delas, ali onde convém, a saber, na borda. (MALEVAL, 2017, p. 168-169).

Em outras palavras, o objeto autístico funcionaria como um verdadeiro ferrolho, que tranca a porta e transforma o espaço interno da criança num regulador de gozo que pode se apresentar nas estereotipias. Mas se isso não for suficiente, o sistema pode entrar em colapso e o sujeito autista pode bater a cabeça contra a parede, alternando, assim, atitudes de retraimento e comportamentos autoagressivos (ORRADO; VIVES, 2021).

Nesta direção, o objeto autístico complexo se inscreve numa lógica parecida a uma cutucação do objeto, visto que ele se esforça por enquadrar o seu excesso de presença e distanciá-lo, produzindo um acionamento precário da dinâmica pulsional e permitindo a instauração de certa animação subjetiva (MALEVAL, 2017). Vejamos o que nos relata Bettelheim (1987, p. 294, grifo nosso) sobre as soluções de Joey para amainar sua angústia e construir seu mundo:

Dominado por máquinas que lhe controlavam o corpo e a mente, e exasperado por elas o dirigirem segundo suas próprias leis e não segundo os desejos dele, Joey reafirmava-se com violência. Quando 'fazia explodir' as lâmpadas ou válvulas que forneciam energia à máquina-Joey, por um instante tornava-se uma pessoa real. Jogando-as fora, libertava-se da escravidão. Era o único instante supremo em que estava vivo. Mas assim que despedaçava a máquina, a vida entrava em declínio e instalava-se a ansiedade. O circuito era interrompido. Seu eu desintegrava-se, esvaziava-se de toda emoção, de toda a energia vital. Tudo era consumido na explosão. 
- | Joey e sua mecânica do "corpo": um olhar sobre a escolha do sujeito autista de se alienar parcialmente à linguagem

Sobre os objetos complexos de Joey, Maleval (2017) aponta uma qualidade comum a todos eles, qualidade esta que Joey tenta adquirir, a capacidade que possuem de regular a energia vital. Joey os utiliza para tratar sua afetividade. Esses objetos são, conforme o autor, "[...] captadores de libido, reguladores de gozo. Traduzem um trabalho subjetivo de tratamento das pulsões" (MALEVAL, 2017, p. 178).

No tocante à progressão dos objetos complexos de Joey, o autor afirma ainda serem frutos de um trabalho defensivo, longo e difícil, com avanços e retrocessos: a automáquina, Kenrad e Mitchell (dois garotos da escola), o amigo imaginário Valvus (menino feito Joey) e o retificador que converte a corrente alternada em corrente contínua (construído quando se especializou em eletrônica) (MALEVAL, 2017).

Para Maleval (2017, p. 219), o retificador construído por Joey exemplifica o que este autor chama de ilha de competência, ou seja, um interesse específico para os estudos de eletricidade que serviu de raiz para o desenvolvimento do seu Outro de síntese. Este último é "[...] construído de elementos linguísticos aprendidos por repetição, ou registrados de maneira fotográfica, que apresentam um caráter objetal muito marcado", como descreve Bettelheim (1987, p. 367) numa visita que Joey fez à escola, três anos depois de sua partida:

O que realmente nos impressionou, muito mais do que o que ele nos contou do passado e da sua presente capacidade de desempenho, foram as duas coisas que ele escolheu trazer consigo para nos mostrar. Uma delas seu diploma de colegial. A segunda coisa foi uma máquina elétrica que construiu sozinho e cuja demonstração fez aos que dentre nós desejassem escutar. Era uma coisa muito pesada e ele a fazia vergar precisamente como as lâmpadas e motores o haviam dominado no passado, mas na forma como ele transportava essa máquina havia triunfo e satisfação. Era um retificador, e sua função consistia em transformar a corrente alternada em corrente contínua. E mostrou-nos várias vezes como esse aparelho que construíra mudava o eterno movimento oscilatório da corrente alternada para um fluxo direto e contínuo. Joey libertarase realmente do círculo vicioso no qual girara incessantemente entre o anseio e o medo. Sozinho, alterara o curso dos acontecimentos e começava agora a relacionar-se diretamente com a vida.

Encontramos, no trecho acima, o que Maleval (2017, p. 220) aponta acerca da função capital do objeto autístico, a de ultrapassar a função de um duplo protetor, uma vez que ele contribui para o estabelecimento de uma energética pulsional. Desse modo, o objeto autístico é um duplo que suplementa a debilidade fálica e obtura a hiância do Outro, já que a realidade do sujeito autista é investir essencialmente no mundo, sua 
relação com a linguagem e os seus objetos por derivação do objeto autístico complexo. É nesse sentido que o autor destaca que o Outro de síntese do autista difere em relação com os significantes que constituem o inconsciente freudiano por dois pontos: primeiro, permanecem parasitados pelo referente, não apagando a coisa representada; segundo, tem seu funcionamento como "godês de gozo" (LACAN, 1971, p. 118) não representam a pulsão, ou seja, apresentam uma ausência de conexão entre a linguagem e a vida emocional.

É nesse sentido que notamos a pertinência do qualificativo proposto por Maleval (2017): ilhas de competência, visto que a seleção de um objeto ou de uma afinidade deve ser considerada uma escolha que supõe um sujeito em devir. Essa escolha ou, como traz Lacan (1998), insondável decisão do ser, nos aponta o caminho que o gozo tomou emprestado. Desse modo, o objeto constitui simultaneamente uma ilha e uma competência para que o trabalho do gozo seja possibilitado, para que o tratamento da dimensão pulsional seja operado a partir da escolha do sujeito autista.

\section{Considerações finais}

O sujeito autista interroga o homem sobre sua relação fundamental com a linguagem, visto que, quand o tem acesso à linguagem, usa-a de maneira bastante particular, o que nos levou a discutir, neste estudo, a escolha do sujeito autista: a de se alienar parcialmente ao Outro da linguagem.

Diante das considerações apresentadas a respeito do modo como o sujeito autista se posiciona frente ao Outro, foi possível percebermos que ele responde ao processo de uma alienação parcial, mantendo-se, consoante Maleval (2018), numa alienação sem o entroncamento do significante mestre, na qual há uma repetição do primeiro significante sem reenvio de mensagem para o outro. Ou seja, um vínculo particular com o significante, com o objeto voz, como forma de mantê-lo à distância. Desse modo, todo o desafio é encontrar um uso específico da voz que permitirá ficar a salvo de toda e qualquer dimensão de endereçamento.

Os recortes apresentados do caso Joey exemplificam um intenso trabalho de uma sucessão de elaborações de borda, que faz um movimento da passagem de máquinas assustadoras a formas cada vez mais humanas e amistosas, testemunhando que a criação da borda não está a serviço de um encapsulamento, mas de um esforço do sujeito autista para tentar retornar ao mundo. 
- Joey e sua mecânica do "corpo": um olhar sobre a escolha do sujeito autista de se alienar parcialmente à linguagem

Tais recortes indicam a necessidade que o sujeito autista tem de separar, realmente, o seu território do mundo que o cerca, seja intensificando seus recursos às estereotipias ou olhando fixamente para um objeto quando seu espírito é invadido. Esse muro é o que Maleval (2017) propõe chamar de borda. Com o uso desse termo, aponta para a função de proteção, ao mesmo tempo em que reconhece um potencial de evolução.

Esses recortes indicam também que a necessidade de imutabilidade por parte do sujeito autista vai favorecer um vínculo único com um objeto ou um tema de predileção e este é, ao mesmo tempo, uma escolha do sujeito e a testemunha do caminho traçado pelo gozo. Assim, o sujeito autista, em sua relação com a linguagem, permanece desconectado do Outro, mas abre uma possibilidade de diálogo com os outros.

\section{Agradecimentos}

A autora agradece o Núcleo de Estudos Psicanalíticos - NINAR/Recife, do qual é membro.

\section{Referências}

BETTELHEIM, B. A fortaleza Vazia. São Paulo: Martins Fontes, 1987.

CATÃO, I.; VIVÈS, J. M. Sobre a escolha do sujeito autista: voz e autismo. Estudos de Psicanálise, Belo Horizonte, n. 36, p. 83-92, 2011.

JAKOBSON, R. Linguística, poética, cinema. São Paulo: Perspectiva, 1971.

LACAN, J. Escritos. São Paulo: Perspectiva, 1998.

LACAN, J. O Seminário 7. Os quatro conceitos Fundamentais da Psicanálise. Rio de Janeiro: Zahar, 2008a [1959-1960].

LACAN, J. Seminário 20. Mais, ainda. Rio de Janeiro: Zahar, 2008b [1972-1973].

LACAN, J. O seminário, livro 18. De um discurso que não seria do semblante. Rio de Janeiro: Jorge Zahar, 2009 [1971].

LEITE, N. V. A. Sobre a singularidade. Cad. Est. Ling., n. 38, p. 39-49, jan./jun. 2000. 
LEITE, N. V. A.; SOUZA JR., P. S. Corpo e língua materna. In: TEPERMAN, D.; GARRAFA, T.; IACONELLI, V. (org.). Corpo. Belo Horizonte: Autêntica, 2021.

LEMOS, C. T. G. Processos metafóricos e metonímicos: seu estatuto descritivo e explicativo na aquisição da língua materna. Trabalho apresentado in The Trento Lectures and Workshop on Metaphor and Analogy; organizado pelo Istituto per la Ricerca Scientifica e Tecnológica Italiano em Povo, 1998.

LEMOS, C. T. G. Sobre os fragmentos e holófrases. Anais do III Encontro LEPSI/USP Campinas: Instituto de Psicologia, Campinas, 2001.

LEMOS, C. T. G. Das vicissitudes da fala da criança e de sua investigação. Cadernos de Estudos Linguísticos, Campinas, n. 42, p. 41-69, jan./jun. 2002.

MALEVAL, J.-C. Da estrutura autista. Revista aSEPHallus de Orientação Lacaniana, Rio de Janeiro, v. 13, n. 26, p. 4-38, maio/out. 2018.

MALEVAL, J.-C. O autista e sua voz. São Paulo: Blucher, 2017.

MALEVAL, J.-C. Por que a hipótese de uma estrutura autística? Opção lacaniana online nova série, ano 6, n. 18, p. 1-40, nov. 2015.

MALEVAL, J.-C. Língua verbosa, língua factual e frases espontâneas nos autistas. In: MURTA, A.; CALMON, A.; ROSA, M. (org.). Autismo(s) e atualidade: uma leitura lacaniana. Belo Horizonte: Scriptum, 2012.

ORRADO, I.; VIVES, J. Autismo e mediação: uma solução para cada um. São Paulo: Aller, 2021.

SAUSSURE, F. Curso de linguística geral. São Paulo: Cultrix, 2006.

SILVA, L. B. M. Música: um estímulo à expressão cognitiva e à linguagem dos bebês. 2015. Dissertação (Mestrado em Música) - Universidade Federal de Goiás, Goiânia, 2015. Disponível em: https://repositorio.bc.ufg.br/tede/handle/tede/4789. Acesso em: 03 mar. 2021. 
- | Joey e sua mecânica do "corpo": um olhar sobre a escolha do sujeito autista de se alienar parcialmente à linguagem

COMO CITAR ESTE ARTIGO: SILVA, Elisangela Maria da. Joey e sua mecânica do "corpo": um olhar sobre a escolha do sujeito autista de se alienar parcialmente à linguagem. Revista do GEL, v. 18, n. 3, p. 386-403, 2021. Disponível em: https:// revistadogel.gel.org.br/

Submetido em: 21/07/2021 | Aceito em: 12/10/2021. 